\title{
METODOLOGIAS ATIVAS - ESTUDO DE CASO: RETENÇÃO E AVALIAÇÃO DE RESULTADOS
}

\section{ACTIVE METHODOLOGIES - CASE STUDY: RETENTION AND EVALUATION OF RESULTS}

\author{
Jadir Perpetuo dos Santos ${ }^{1}$, Alex Paubel Junger², Luiz Henrique Amaral ${ }^{3}$, Alexandre Acácio de Andrade \\ RESUMO
}

Esta pesquisa tem como objetivo identificar fatores estimulantes de conhecimento na perspectiva do aluno e retenção de alunos nas Faculdades de Tecnologia, aplicar esses fatores em metodologias ativas e fazer um comparativo de aprendizado entre a metodologia tradicional e a ativa. Para isso, o trabalho apresenta um framework descrevendo que a metodologia aplicada se iniciou com a leitura de referenciais teóricos em fontes primárias sobre metodologias ativas, criando-se um questionário semiestruturado, aplicado aos alunos de diversos cursos de tecnologia. Com esses resultados desenvolveu-se, pela abordagem dedutiva, uma aula (estudo de caso) com metodologias ativas. Os resultados foram: $69,2 \%$ dos alunos preferem metodologia ativa à tradicional, considerando-as dinâmicas, motivadoras, são de fácil entendimento entre teoria e prática. Entre os fatores estimulantes têm-se: aulas dinâmicas mesclando metodologias ativas e aulas tradicionais; a qualidade dos professores está entre os fatores de retenção.

PALAVRAS-CHAVE: Metodologias ativas. Retenção. Estudo de caso.

1 Pós Doutorando (pesquisador) em Engenharia de Produção e Inovação na UFABC. Prof. Dr. na FATEC ITAQUERA, ZONA LESTE e IPIRANGA, Prof. na Universidade Cruzeiro do Sul, avaliador do INEP, foi professor de pós-graduação na UniPaulistana e ESTÁCIO. Doutor em Engenharia Mecânica pela UNICAMP, Mestrado em Administração pela Universidade Cidade de São Paulo, Especialização em Docência de Nível Superior, Pós-graduação em Engenharia de Produção, Engenharia de Qualidade pela Universidade São Judas Tadeu com Pós-graduação em Administração da Produção e Graduação em Administração de Empresas pela Universidade Municipal de São Caetano do Sul. Professor-Tutor de curso EAD e conteudista. Revisor das revistas GEPROS e EXACTA. Parecerista em congressos: SIMPEP; ENEGEP e CONBREPRO. Autor do livro: Logística reversa, sustentabilidade e educação. Professional Coach of Life. Participante dos commitees: CE-014, ABNT/CEE093 e ABNT/CB-025. Possui experiência com mais de 25 anos nas áreas de: Administração (onde gerenciou equipes multidisciplinares em multiprojetos), Produção (Consultor, Gerente de produção, PCP, Compras, Cronoánalises e melhorias de métodos e processos, ergonomia, etc.) e Qualidade (Consultor em certificações de empresas, e Auditor em certificações de sistemas de gestão, com mais de 450 auditorias nas normas ISO 9001, OSHAS 18001, SA 8000, SEDEX e códigos de condutas). Examinador do Prêmio Examinador do Prêmio Nacional da Qualidade no ano 2000; Examinador do Prêmio Policia Militar da Qualidade nos anos 2002; 2004; 2017 e 2018; Examinador do Prêmio Paulista de Qualidade em Gestão nos anos 2002 e 2005.

2 Pós - Doutor em Engenharia e Gestão da Inovação (UFABC), Doutor em Energia pela Universidade Federal do ABC e Mestre pelo Programa Interdisciplinar em Educação, Administração e Comunicação da Universidade São Marcos, possui graduação em Comunicação Social e Letras - Português/Inglês, com Especialização em Língua Portuguesa. Atualmente é docente permanente do Programa de Pós-graduação em Ensino de Ciências e Matemática da Universidade Cruzeiro do Sul, orientando trabalhos de mestrado e de doutorado na área de Ensino. Atuando, concomitantemente, como professor vinculado a Graduação/Pós-Graduação da Faculdade Tecnológica Termomecânica, na área de Orientação para Inovação, Comunicação e Ensino, com ênfase em Gestão do Conhecimento Organizacional, bem como Pesquisador Colaborador vinculado a Universidade Federal do ABC. Além de atuar como avaliador institucional do Ministério da Educação.

3 Graduado em Física pela Universidade Estadual de Londrina (UEL), mestrado e doutorado em Astrofísica pela Universidade de São Paulo (USP). Especialista em Gestão e Liderança Universitária pela Organização Universitária Interamericana (OUI) em convênio com o Conselho de Reitores das Universidades Brasileiras (CRUB) e UNESP, com estágio profissional realizado na Universidade de Montreal - Canadá. É Professor titular do Grupo Cruzeiro do Sul Educacional, e docente permanente do Programa de Pós-graduação em Ensino de Ciências e Matemática da Universidade Cruzeiro do Sul, orientando trabalhos de mestrado e de doutorado na área de Ensino.

4 Engenheiro eletricista graduação com Ênfase em Energia e Automação (1997), mestre em Engenharia Elétrica (Automação) (2001) e doutor (2007) em Engenharia Elétrica (Automação) todos pela Escola Politécnica da Universidade de São Paulo. Possui trajetória que se dividiu entre as atividades de ensino e a prática de Engenharia. Como professor, transitou pelo ensino médio ainda cursando a graduação - lecionou durante quinze anos para graduação de Engenharia, bem como especializações e pós-graduações. Elaborou e executou projetos de automação industrial por doze anos onde teve oportunidade de trabalhar com algumas das maiores empresas do mercado brasileiro como Petrobras, DuPont, Rhodia, Termag, Colgate, Unilever. Alumar, Vale e Carbocloro. Professor em regime de dedicação exclusiva da UFABC desde 2012 


\section{ABSTRACT}

This research aims to identify stimulating factors of knowledge in the student's perspective and retention of students in the colleges of technologies, apply these factors in active methodologies and make a comparative learning between the methodology Traditional, for this work presents a framework describing that the methodology applied, began with the reading of theoretical referential in primary sources on active methodologies, creating a semi-structured questionnaire applied to students of several technology courses, with these results developed through the deductive approach a class (case study) with active methodologies, the results were: the active methodology does not have results inferior to the face, it is evident that $69.2 \%$ of students prefer active to traditional methodology, considering them: motivating dynamics is easy to understand between theory and practice. Among the stimulating factors are: Dynamic classes merging active methodologies and traditional classes; Objective lessons, giving students an opportunity to express themselves; Reduction of extra activities, to help the student to organize, when possible. The quality of the teachers is among the retention factors.

KEYWORDS: Active methodologies. Retention. Case study. 


\section{INTRODUÇÃO}

Moran (2015), Machado (2017), Diesel, Baldez, Martins (2017) descreveram que a educação formal tinha um dilema: se atualizar de forma ágil, em virtude de as dinâmicas sociais, políticas culturais e tecnológicas estarem em mutação constante. A escola do passado está morrendo, assim ela também tem que evoluir suas competências cognitivas que não se adquire de maneira passiva, não se adquire pelas informações dos professores, para que o aluno possa aprender e, posteriormente, aplicará o conhecimento adquirido acessando a 'nuvem'.

Um processo de aprendizagem busca, constantemente, novas formas de aprendizado, práticas essas que procuram potencializar o conhecimento dos discentes, tornando-os mais críticos. Uma das formas de aprendizado mais recentes são as metodologias ativas, pois ela possibilita que o aluno participe do processo de construção do saber, dando-lhe autonomia para escolha de suas decisões de forma dinâmica e não linear, sendo ajudado pela exponencial criação de ferramentas tecnológicas que dão suporte às metodologias ativas, além, é claro, do conhecimento dos professores e profissionais que as desenvolvem.

Essas metodologias têm apoio da rede educacional, pela transformação que ocasionam em seus alunos e docentes, tornando-os atores da construção do conhecimento. As escolas estão percebendo que as matrizes curriculares devem ser alteradas de maneira mais dinâmica para atender as necessidades do mercado de trabalho e das áreas de pesquisa, assim a autonomia e recursos materiais ou tecnológicos devem ser desenvolvidos para que o docente possa trabalhar questões do cotidiano dos alunos e aproximarem as escolas cada vez mais às práticas reais para construção, análise e resolução de problemas reais através de uma educação potencializada e concreta saindo do uso da memória somente para o entendimento do problema e o uso de ferramentas para sua resolução.

Segundo Quintilhano et al (2017), as DCN's (Diretrizes Curriculares Nacionais) "trazem em seu corpo a intenção de alterar a base filosófica do curso, focando no desenvolvimento de habilidades por meio de uma abordagem pedagógica centrada no aluno."

Gemignani (2012) apud Zalusku e Oliveira (2018) relatam que os conteúdos didáticos das matrizes curriculares são ineficientes para a vida profissional, pois com o passar dos tempos novas complexidades vão surgindo e novas competências são necessárias para com o trabalho que está em constante transformação, pode-se lembrar dos conceitos socráticos de que o conhecimento somente é útil quando ele for aplicado e necessário exercitá-lo em sala de aula.

A aula com metodologias ativas torna-se um ambiente adequado para aplicação de conhecimento interdisciplinar, onde o aluno pode buscar respostas aos problemas de diversas fontes. Sendo uma delas de forma colaborativa, ultrapassando os limites de uma só área, essa interdisciplinaridade representa os problemas do cotidiano enfrentados por qualquer profissional, assim facilitando ao aluno a aplicação do conhecimento fora do ambiente escolar, quando for solicitado (MASETTO, 2011).

Nesse cenário, as metodologias ativas utilizamse de experiências reais ou simuladas nas quais o aluno pode se envolver para resolver diferentes problemas de interação social com os demais participantes da sala ou do grupo, tornando-se, assim, uma ferramenta eficaz no ensino e aprendizagem, que lhe proporciona o aprender, centrado na pedagogia crítica, reflexiva e interativa de maneira interdisciplinar, por meio de um ensino híbrido (Blended) baseado em desafios para desenvolvimento de habilidades, por meio da participação do aluno (MORÁN, 2015; ZALUSKU, OLIVEIRA, 2018; QUINTILHANO, 2017).

A motivação para esta pesquisa foi a participação em um projeto da FATEC com a Fundação Telefônica, para estimular projetos que atendem aos 17 (ODS) Objetivos de Desenvolvimento Sustentado, agenda 2030, conforme apresentados na figura 1 a seguir.

Figura 1 - (ODS)Objetivos de Desenvolvimento Sustentável

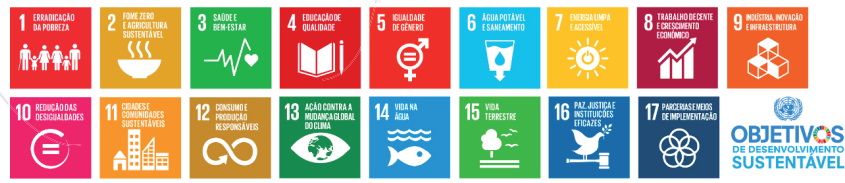

Fonte: ONUBR (2018)

A escolha para o projeto foi o Objetivo 4 (Educação de Qualidade), onde em seu item 4.4 descreve 
que "Até 2030, aumentar substancialmente o número de jovens e adultos que tenham habilidades relevantes, inclusive competências técnicas e profissionais, para emprego, trabalho decente e empreendedorismo" (ONUBR, Item 4.4, 2018).

Para esse objetivo veio a reflexão, de que todos estão querendo que a educação tenha meios de meIhorar as competências técnicas dos alunos, uma delas são as metodologias ativas, mas não evidenciamos pesquisa relatando a percepção dos alunos sobre o que realmente pode aumentar o desempenho cognitivo, portanto, o objetivo desse trabalho foi identificar os fatores estimuladores de conhecimento.

Para Diesel, Baldez, Martins (2017), a intenção de ensinar deve existir considerando a perspectiva de que o aluno participará dela atuando diretamente na solução de problemas reais, dessa maneira impactará na redução de evasão dos alunos, aplicando o que for considerado objeto da aprendizagem da metodologia ativa.

\section{REFERENCIAL TEÓRICO}

As reflexões dos autores, a seguir, têm o objetivo de facilitar o entendimento da pesquisa aqui realizada.

\subsection{COMPREENDENDO METODOLOGIAS ATIVAS}

As escolas estão procurando formas diferentes de ensinar, por meio de casos, jogos, leituras, quizzes, simulações, desafios relevantes em times ou individualmente, por isso uma adequação da grade curricular é necessária (MORÁN, 2015).

Para Morioka, Dantas e Silva (2018), existem dois tipos de metodologias ativas: Indutivas (procuram atender as DCN's) e Dedutivas (é motivado a aprender algo útil para sua vida. Reagindo a estímulos comportamentais, assimilando o conteúdo levando-o a experiências práticas, construindo seu aprendizado).

O motivo de chamar-se metodologia ativa é a existência da participação dos alunos em atividades práticas, tornando-se atores do aprendizado, que se elaboram situações em que os discentes, por meio de um problema, articulam o conhecimento interdisciplinar, saindo das paredes da sala de aula, desenvolvendo estratégias cognitivas, entre outras, com possibilidade de conhecimento exponencial, através de atividades por pares, aprendizagem baseada em problemas e em projetos, sala de aula invertida, ensino híbrido, etc., para superar obstáculos (DIESEL, BALDEZ, MARTINS, 2017; FONSECA, MATAR NETO apud LAZARO, SATO, TERANI, 2018; CAMARGO et al, 2017).

A aplicação da metodologia ativa proporciona ao aluno assimilar maior volume de conteúdo, retenção de informações por mais tempo com aulas mais prazerosas. Assim, vivenciando os conteúdos na prática, o aluno torna-se mais seguro na aplicação do conhecimento, reforçando sua autonomia em tomadas de decisões, senso de responsabilidade, iniciativa criadora, cooperação, espírito crítico e, com o trabalho em equipe/grupo, melhora suas características de relacionamento e liderança, tornando o aluno o principal agente na aprendizagem, promovendo seu próprio desenvolvimento (ZALUSKI; OLIVEIRA, 2018).

Para que o aluno se aproprie do empoderamento das metodologias ativas, segundo Zaluski e Oliveira (2018, p. 5), "deve ler, escrever, perguntar, discutir ou estar ocupado em resolver problemas e desenvolver projetos. O aluno deve realizar tarefas mentais de alto nível, como análise, síntese e avaliação". Reforçado pela reflexão de Moran (2015, p. 3), quando diz que "queremos que os alunos sejam proativos, precisamos adotar metodologias que os envolvam em atividades cada vez mais complexas, que tenham que tomar decisões e avaliar resultados, com apoio de materiais relevantes", pois a emoção é forte componente de fixação do entendimento e aprendizado, construindo uma relação entre fatos e objetos na reconstrução e produção do conhecimento, superando a educação tradicional com atitude passiva e reprodutora, Zaluski e Oliveira (2018, p. 6), relata que

[...] existem 7 habilidades básicas que estão faltando na formação dos estudantes, sendo elas: (1) fazer boas perguntas; (2) nomear objetos tecnológicos; (3) modelar processos e sistemas qualitativamente; (4) decompor problemas complexos em problemas menores; (5) coletar dados para análise; (6) visualizar soluções e gerar novas ideias; e (7) comunicar soluções de forma oral e por escrito. 
O projeto pedagógico tem-se cada vez mais de se aprender fazendo, ou seja, cada vez mais "blended, misturada, híbrida, saindo fora do ambiente da sala de aula, mas, nos múltiplos espaços do cotidiano, que incluem os digitais [...] com as tecnologias móveis, equilibrando a interação com todos e com cada um", relata Moran (2015, p. 2).

O planejamento de uma aula deve: (i) ter um problema a ser resolvido; (ii) um professor para orientar como buscar e registar as informações, dar apoio, acolher, estimular, valorizar, orientar e inspirar o aluno, ajudando-o a ir além de onde conseguiria fazê-lo sozinho; (iii) somar ideias de todos os colegas e organizá-las; (iv) tentar resolver o problema ou entender o cenário proposto; (v) registrar as lições aprendidas; (vi) o professor deve fornecer um ciclo de aprendizado por meio de feedback positivo, e controlar o tempo, durante todas as etapas da atividade aplicada (MASETTO, 2011; MORAN, 2015). O planejamento das aulas deverá ser direcionado para os docentes e sua aprendizagem, em busca de melhor empatia do aluno com as problemáticas por ele confrontadas, os princípios que constituem as metodologias são apresentados na figura 2, a seguir, (DIESEL, BALDEZ, MARTINS, 2017).

Figura 2 - Princípios das metodologias ativas

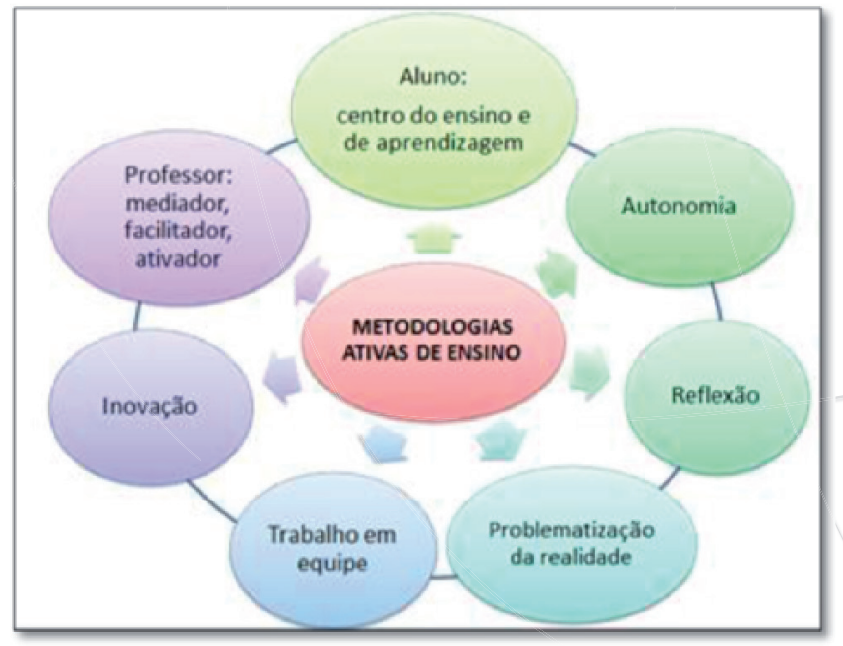

Fonte: Diesel, Baldez, Martins (2017)

Para aplicação de metodologias ativas, é necessário ter um equilíbrio entre a prática e a teoria, acompanhando os objetivos propostos por cada conteúdo prático e diretrizes curriculares nacionais, auxiliando em tomadas de decisões complexas (MORÁN, 2015).

Para Poisson (2018), "as metodologias ativas de aprendizagem na perspectiva de integrar teoria e prática, ensino e serviço como forma de favorecer a motivação autônoma e minimizar dificuldades de aprendizagem. " Para Berbel (2011) apud Poisson (2018), "metodologias ativas baseiam-se em formas de desenvolver o processo de aprender, utilizando experiências reais ou simuladas, visando às condições de solucionar, com sucesso, desafios advindos das atividades essenciais da prática social, em diferentes contextos", apoiando esse conceito Bates (2016) apud Poisson (2018) cita que "metodologias ativas ou aprendizagem experiencial têm como princípios centrais, promover a reflexão sobre as experiências dos estudantes na ação de executar algo para incorporar conhecimento conceitual e experiência prática".

Para Moran (2013, p. 1)

A aprendizagem é mais significativa quando motivamos os alunos intimamente, quando eles acham sentido nas atividades que propomos, quando consultamos suas motivações profundas, quando se engajam em projetos em que trazem contribuições, quando há diálogo sobre as atividades e a forma de realizá-las.

Quando os alunos se envolvem para resolver uma atividade com sua vida fora de aula, trabalham o pensamento crítico, criativo etc., e os discentes são avaliados na entrega do projeto. Buck Institute for Education (2008, p. 18) apud Moran (2013, p. 12) identifica alguns atributos para que um projeto seja efetivo:

a) Reconhecem o impulso para aprender, intrínseco dos alunos;

b) Envolvem os alunos nos conceitos e princípios centrais de uma disciplina;

c) Destacam questões provocativas;

d) Requerem a utilização das ferramentas e habilidades essenciais, incluindo tecnologia para aprendizagem, autogestão e gestão do projeto;

e) Especificam produtos que resolvem problemas;

f) Incluem múltiplos produtos que permitem feedback; 
g) Utilizam avaliações baseadas em desempenho; e

h) Estimulam alguma forma de cooperação.

\subsection{HOUSEKEEPING}

O Housekeeping também conhecido como programa 5 S's, procura, pelo envolvimento e participação de todos, criar condições adequadas de trabalho.

Conhecido desde a década de 50, no Japão, desenvolvido por Kauro Ishikawa baseado em 5 sensos (Seiri- Utilização, Seiton-Ordenação, Seiso-Limpeza, Seiketsu-Bem-estar e Shitsuke-Autodisciplina) comuns para gerar maior produtividade e qualidade na melhoria do ambiente de trabalho, tornou-se um referencial de organização, pela melhoria de processos, redução dos desperdícios, riscos de acidentes, falhas etc., uma vez que é a base para todos os outros programas de qualidade, quando alinhado à visão estratégica de uma organização (SILVA et al, 2016; PAIVA, ZOCCHE, 2018; OLIVEIRA, FARIAS, 2017).

\section{METODOLOGIA}

A estrutura deste trabalho adotou o seguinte framework explicado a seguir:

Figura 2 - Framework da estrutura metodológica do artigo

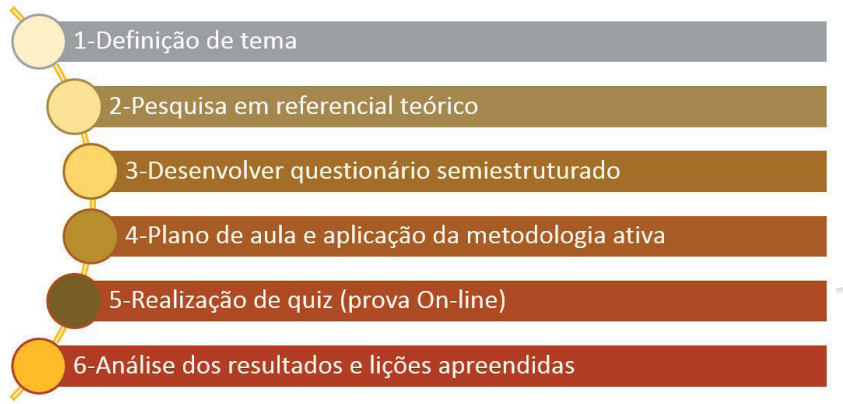

Fonte: Os autores (2018)

A primeira etapa foi a definição de um tema para o projeto Pense Grande, o escolhido foi Metodologias Ativas.

A segunda etapa foi fazer uma pesquisa sobre os referenciais teóricos em fontes primárias sobre o tema Metodologias Ativas, entender o que os autores estavam discutindo sobre o tema, para auxiliar na tra- tativa do problema, como descreve Lakatos e Marconi (2015) e desenvolver um plano de trabalho.

A terceira etapa foi desenvolver um questionário semiestruturado no Google Forms, para identificar o que os alunos entendem como boas práticas em sala de aula e o que os motivam. O questionário foi enviado a todos os alunos, e realizou-se uma observação direta, segundo definições de Lakatos e Marconi (2015). Após o fechamento desse questionário, houve um feedback aos alunos sobre um tema da disciplina, dentro dessas solicitações e, ao término, foi feito um quiz para avaliar a absorção do tema que foi escolhido: o Housekeeping ou também conhecido como 5 S's. O mesmo questionário foi aplicado em outra sala de outro curso com aulas tradicionais.

A quarta etapa foi desenvolver o Plano de Aula para definir quais metodologias ativas (vídeos, cartazes, aplicação prática na empresa ou em sua residência) usar e aplicar a metodologia em sala de aula e em ambiente profissional e pessoal (caso o aluno não esteja trabalhando) com as atividades de metodologias ativas, através da abordagem dedutiva, para se avaliar os resultados dessa aplicação aos alunos de tecnologia, através do estudo de caso, com observação direta extensiva que, segundo Lakatos e Marconi (2015), tem-se o uso de questionário, semiestruturado aplicado na terceira etapa, onde a população será todos os alunos da sala que aplicar-se-á a metodologia ativa, para avaliar os resultados entre a aula tradicional comparando-a com a metodologia ativa.

A quinta etapa é a realização do quiz para avaliar a absorção dos alunos e comparando os resultados das aulas tradicionais com metodologia ativa e fornecer feedback desses resultados.

A sexta etapa é a análise desses resultados através da lição aprendida, para mitigar impactos negativos em futuros trabalhos com metodologia ativa.

\section{DESENVOLVIMENTO DO ESTUDO DE CASO}

O desenvolvimento dessa pesquisa foi realizado em uma Faculdade Estadual com foco em cursos de Tecnologia no Estado de São Paulo. Diversos cursos foram pesquisados e os cursos escolhidos para aplicação foram: Tecnologia em Processos de Fabricação (aula com metodologia ativa) e Tecnologia e Automação Mecânica (aula tradicional). 
As fases a seguir descritas iniciam-se após a identificação do problema e a leitura do referencial teórico (fontes primárias).

\section{Fase 1}

Após realizar uma leitura sobre o tema, desenvolveu-se um questionário inicial para verificar quais são os motivadores em aula. Esse questionário foi disponibilizado para todos os alunos de todos os cursos em que leciono.

\section{Fase 2}

Para divulgação desse questionário foram usados os e-mails dos alunos, comunicados em sala de aula e um link com o questionário, para ser preenchido on-line. Este foi desenvolvido na plataforma Google For$m s$ e as questões utilizadas com suas respostas foram:

\section{Questão 1 - Qual seu curso?}

Figura 3 - Relação de cursos que responderam ao questionário de percepção

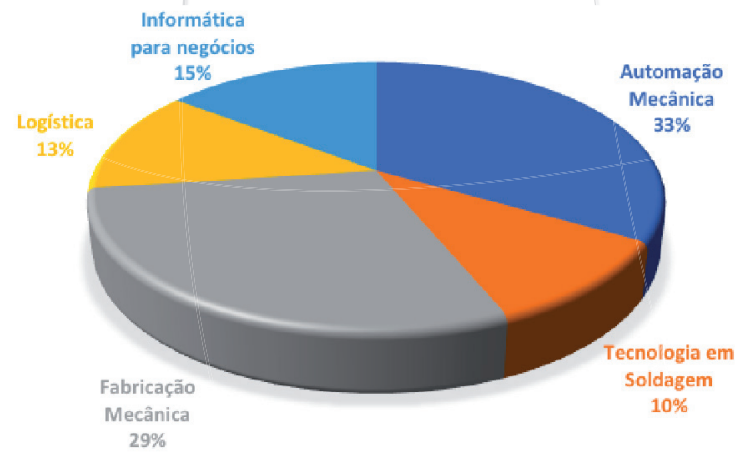

Fonte: Os autores (2018)

A figura 3 apresenta a participação de 5 cursos diferentes na avaliação da percepção sobre metodologias ativas, o que valida o trabalho.

\section{Questão 2 - Como você acredita que tem maior absorção da matéria dada em aula?}

Figura 4 - Fatores que auxiliam na absorção da matéria dada.
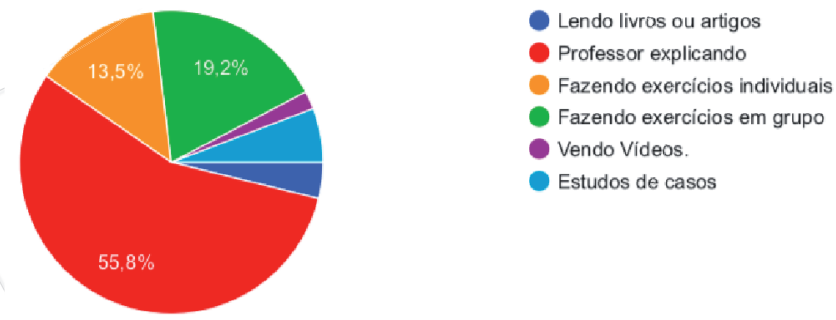

Lendo livras ou artigos

Professor explicando

Fazendo exercicios individuais

- Fazendo exercicios em grupo

Vendo Vídeos.

Estudos de casos

A figura 4 apresenta que os alunos acreditam na explicação do professor $(55,8 \%)$ e em exercícios em grupo (19,2\%), como melhor fonte de absorção da matéria dada em aula.

\section{Questão 3 - As disciplinas que você mais gosta} desenvolve?

Figura 5 - Temas que desenvolvem as disciplinas preferidas pelos alunos.
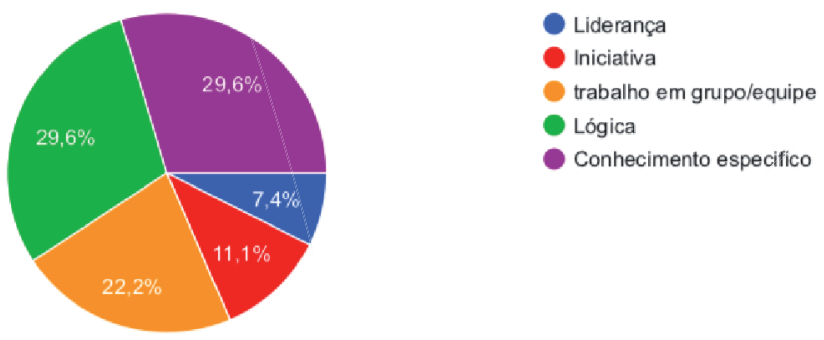

Fonte: Os autores (2018)

A figura 5 apresenta que existem dois valores em igualdade sobre as disciplinas que os alunos mais gostam: desenvolvem a Lógica e Conhecimento específico com $29,6 \%$ e, em terceiro, as que aplicam trabaIho em grupo e em equipe. 


\section{Questão 4 - Quais são os fatores de retenção do aluno em uma universidade?}

Figura 6 - Fatores de retenção dos alunos na universidade.

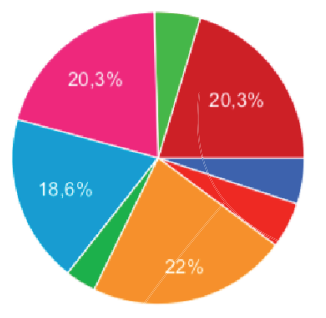

$$
\begin{aligned}
& \text { Proximidade } \\
& \text { Acesso Fácil } \\
& \text { Qualidade dos professores } \\
& \text { Valor Baixo da mensalidade interna } \\
& \text { Gratuidade do curso } \\
& \text { Métodos de aprendizagem } \\
& \text { Infraestrutura } \\
& \text { Metodologia em sala de aula pelos } \\
& \text { professores }
\end{aligned}
$$

Fonte: Os autores (2018)

Comentários adicionais sem correção ortográfica: "Visitas técnicas, palestras específicas para a área de formação; Qualidade da instituição; A proximidade e o acesso fácil também; o conteúdo da matéria ser extenso e a aula se torna improdutiva porque o professor precisa cumprir o cronograma da faculdade."

Para os alunos entrevistados, os fatores que mais retêm o aluno na universidade são: Qualidade dos professores (22\%); Método de aprendizagem $(20,3 \%)$ e metodologia em sala de aula usada pelos professores.

Questão 5 - Qual a periodicidade de realização de avaliação você acredita ser a mais produtiva no semestre?

Figura 7 - Melhor periodicidade para realizar as provas.

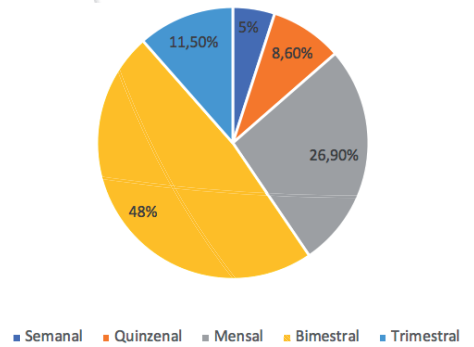

Fonte: Os autores (2018)

Para os alunos entrevistados, uma boa periodicidade de realização de provas é bimestral (48\%) ou mensal $(26,9 \%)$.

\section{Questão 6 - Uma aula produtiva deve ter?}

Figura 8 - Fatores que tornam uma aula produtiva.

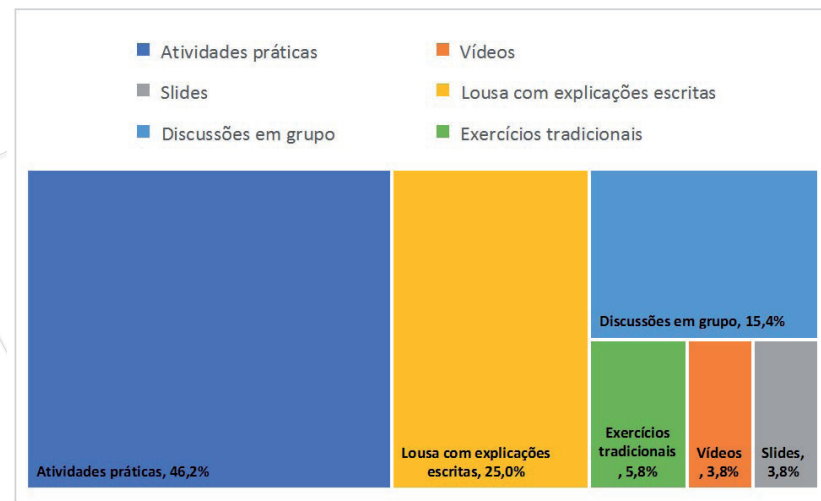

Fonte: Os autores (2018)

A figura 8 apresenta que uma aula, para ser produtiva, deve ter atividades práticas $(46,2 \%)$ com explicações na lousa (25\%).

\section{Questão 7 - Em sua percepção qual é o melhor papel do professor em sala de aula?}

Figura 9-Qual o papel do professor em sala de aula.

Fonte: Os autores (2018)

A figura 9 apresenta que os alunos acreditam que o papel do professor é fornecer informações em sala de aula, onde a apresentação do conteúdo auxilia o entendimento do aluno sobre o tema $(61,5 \%)$. 


\section{Questão 8 - 0 que mais estimula o aluno em aula?}

Figura 10 - Fatores que estimulam o aluno em sala de aula.

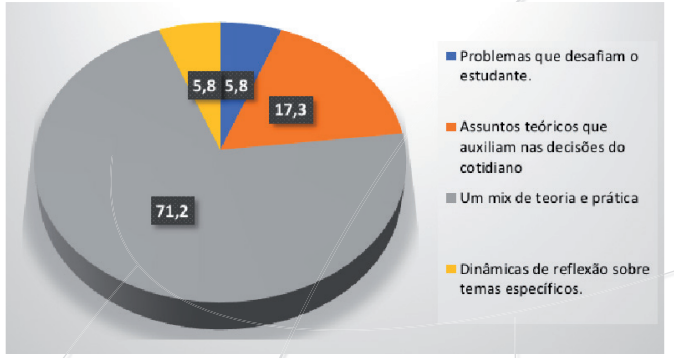

Fonte: Os autores (2018)

Comentários adicionais sem correção ortográfica: "Exemplos reais e atuais; Além de um professor com um bom conhecimento do assunto e participativo."

A figura 10 apresenta que o mix de teoria e prática $(71,2 \%)$ é o que mais estimula o aluno.

Questão 9-O que compromete o desempenho do aluno na escola?

Figura 11 - fatores que comprometem o desempenho do aluno na sala de aula.

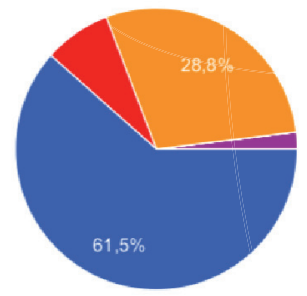

- Falta de tempo do aluno para estudar

Dificuldades de aprendizado

Didática do professor

Empatia ao professor

Falta de desafiós

Fonte: Os autores (2018)

Comentários adicionais sem correção ortográfica: "O tempo dedicado pelo aluno para ir à faculdade, na minha opinião, em todas as matérias, deve ser aproveitado ali. Muitos alunos não possuem muito tempo disponível para atividades extraclasse."

A figura 11 apresenta que, para os alunos, a falta de tempo $(61,5 \%)$ é o maior comprometedor de seu desempenho. Em seguida, a didática do professor $(28,8 \%)$.

\section{Questão 10 - Aulas que são estimulantes têm?}

Figura 12 - O que tem uma aula estimulante.

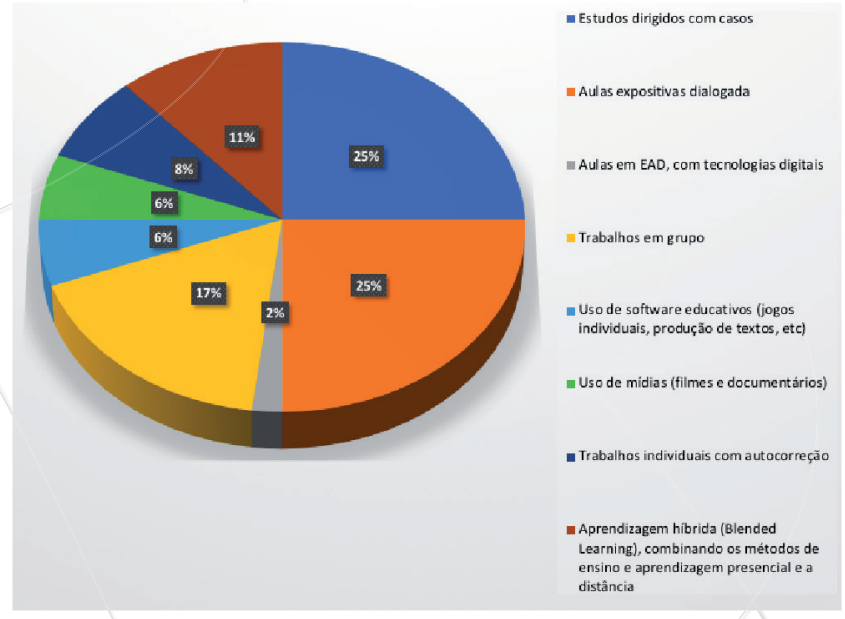

Fonte: Os autores (2018)

A figura 12 apresenta que o que mais estimula o aluno em sala de aula é: estudos dirigidos (25\%), aulas expositivas e dialogadas (25\%) e trabalhos em grupo (17\%).

\section{Questão 11 - Qual competência você acredita ser mais importante para o desenvolvimento do tecnólogo?}

Figura 13 - Competências importantes para os alunos.

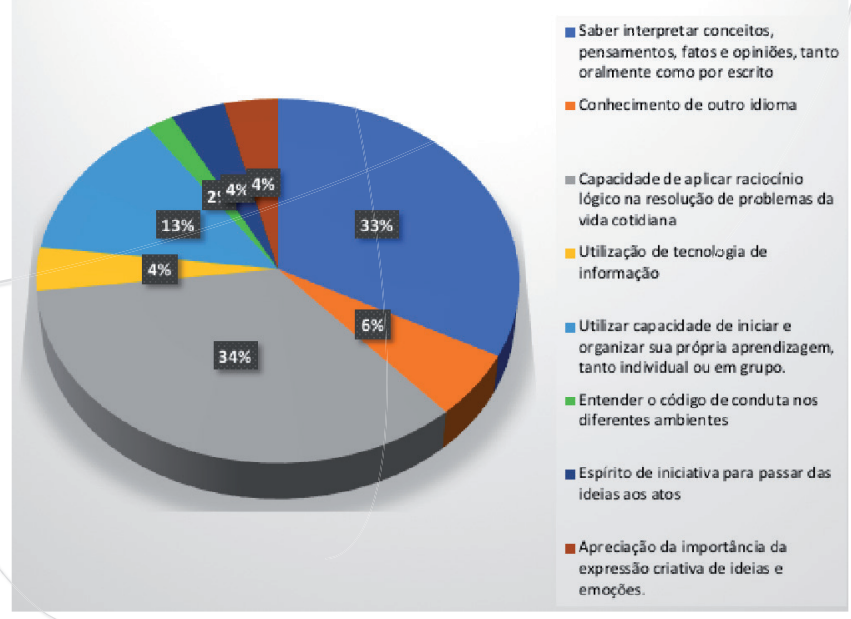

Fonte: Os autores (2018)

Para esse item, as alternativas consideradas foram as Competências-chaves essenciais recomendadas pelo Parlamento Europeu, descritas na disser- 
tação de mestrado do professor Pamboukian (2018, p. 56 ), portanto, ao ver a figura 12 , tem-se que os alunos entendem que as competências mais importantes para um tecnólogo são: Competências matemáticas e competências básicas em ciências tecnológicas (34\%); Comunicação da língua materna, que consiste na capacidade de expressar e interpretar conceitos, pensamentos e sentimentos, fatos e opiniões (33\%) e capacidade de iniciar e organizar sua própria aprendizagem (13\%). Consideradas menos importantes: conhecimento de outro idioma; competências sociais e cívicas; espírito de iniciativa empresarial e sensibilidade e expressão cultural.

\section{Questão 12 - Qual a característica do professor que você mais admira?}

Figura 14 - Características de um professor admirado.
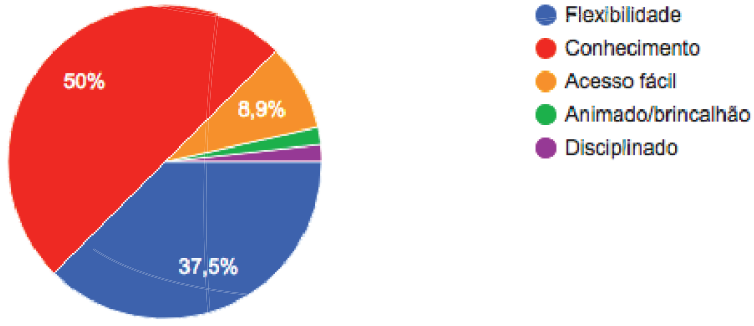

Fonte: Os autores (2018)

Comentários adicionais sem correção ortográfica: "Focar em tecnologia do qual se trata o curso; Dominar a disciplina ministrada, expor experiência e estudo de casos; Além de ser uma pessoa inteligente, demonstra interesse de que os alunos aprendam sua matéria, não somente expõe e deixa para que os alunos se virem, gosta que os alunos interajam entre si."

A figura 14 apresenta as características mais importantes para um professor. São elas: Conhecimento $(50 \%)$ e Flexibilidade $(37,5 \%)$.

\section{Questão 13 - 0 que é necessário para motivá-lo(a) em sala de aula?}

Respostas sem correção ortográfica: "Atividades práticas que justifiquem a teoria dada; Uma boa explicação do tema e exercícios de exemplos para as- similar o tema; Atividades que possibilitem experiência prévia de casos reais e sua resolução. Conciliando teoria e prática em grupo; Quem ministra, falar sobre vivências e suas experiências; Desenvolver situações reais da indústria, com o objetivo de solucionar problemas ou implementar projetos; Poder aplicar na vida profissional os conhecimentos e conceitos adquiridos através de exemplos práticos, por exemplo. Interação, discussões e atividades em grupo; Conseguir assimilar os conteúdos e desenvolvê-los na prática; Aulas bem elaboradas; Exercícios e explicações diretas; Paciência para explicar conteúdo dinâmico, bem explicado e com aplicações práticas; O professor ter domínio da matéria e exercícios para absorção do conteúdo; Dinâmica em grupo; Assunto Interessante; Um professor com boa didática que incentiva o aluno a estudar, o que não ocorre em algumas matérias, por exemplo; ter algum tipo de desafio; Boa didática do professor; Professor entender o aluno; Aulas expositivas com áudio, vídeo, slide, teoria e prática; Que a aula tenha o conceito, porém alinhada com exercícios; Aulas que não se resumem apenas em textos e slides, é necessária a discussão em grupo, entre os alunos e o professor."

\section{Questão 14 - Qual sua principal dificuldade na universidade?}

Respostas sem correção ortográfica: "Falta de tempo para estudar; artigo científico; Didática e métodos de avaliação muito diversificados entre professores do mesmo semestre; Falta de flexibilidade do professor em explicar um assunto, ou falta de conhecimento da matéria; Excesso de slides com pouca prática do assunto tratado; Conhecimento logico sou fraco nesse quesito; Aulas ao sábado; Conciliação entre faculdade, trabalho e família; Dificuldade em alguns temas; Interpretação de questões de atividades (alguns professores); O horário, algumas tarefas e também mudanças que ocorre no ano; Levando em consideração que sou autônomo! Alguns professores que não acompanharam a evolução da sociedade e permanecem com conceitos retrógrados. Aplicar os conhecimentos na vida profissional; Desafios que são colocados para os alunos tentarem fazer sem ter previa introdução, para ser explicado posteriormente: Exemplificando: o professor pede pra fazer um código em Java, mas não ensina como fazer. $\mathrm{E}$ depois que vocên não consegue fazer, o professor 
mostra o código pronto, atrapalhando todo o aprendizado; O aluno fica desmotivado por tentar e tentar e não conseguir realizar, e acaba desanimando da matéria. Falta de didática e carisma de alguns professores; Ter professores que não conseguem lecionar e nem ter um canal efetivo para resolver; Interpretação de problemas; Inglês; Lidar com as metodologias mirabolantes e/ou injustas de alguns professores; Manter o foco nas atividades ou explicações. A minha dificuldade é mesmo com as burocracias internas de recepção/diretoria por conta de horários, ajustes, auxílio e ajuda para com os estudantes; ser mais envolvido com as matérias."

\section{Questão 15 - Caso o rendimento não seja satisfatório, quais medidas podem ser adotadas no processo para a recuperação de aprendizagem do aluno?}

Respostas: "Atividades práticas focadas; Sempre que possível fazer um autoconhecimento do aluno e avaliá-lo; Atividades para o aluno ter a possibilidade de recuperar nota; Explicações e atividades práticas e fáceis acho que talvez poderia passar trabalho; $\mathrm{O}$ ato de ensinar no período de aula, não faria o rendimento de alunos caírem; Rever os tópicos de maior dificuldade do aluno e realizar atividades; Atividades complementares na sala de aula, dinâmicas participativas sobre o assunto estudado; Caso seja identificada logo no início a dificuldade, talvez mudando a abordagem sobre o tema. Bastante exercício, passo a passo; Estudar usando os livros da disciplina e o Youtube com as videoaula; Aulas especializadas da matéria; Trabalhos em grupo; Aulas de reforço; Atividades para repor rendimento; Cursos específicos da disciplina; Mais Trabalhos mais práticos ou até mesmo avaliações mais práticas, visto que em provas nós acabamos tendo que decorar muita teoria; Atividades em sala de aula. Alguns alunos precisam escrever para entender e pôr em prática o que foi passado para de fato aprender; Entendi que após a P1, os professores deveriam interagir com os alunos que obtiveram menor rendimento para a recuperação destes para a P2, utilizando os outros alunos com melhor desempenho; fazendo rodízio de professores em determinadas matérias; Disponibilidade de monitoria pra todas as disciplinas. Existem para somente algumas, e isso é algo muito ruim; Apresentação de seminário; Desen- volvimento através de livros e artigos; Conversar com o aluno, para saber qual está sendo sua dificuldade e propor algo novo; repassar conteúdo quando grande parte dos alunos não entenderam a matéria; Métodos mais intuitivos de aprendizagem, como vídeos e imagens; Trabalhos, revisões; Adotar mais flexibilidade se caso o aluno trabalhe faz estágio. Tanto com faltas quanto outros trabalhos externos específicos para cada um."

\section{Questão 16 - Você cursa a faculdade por quê?}

Figura 15 - Motivação para fazer a faculdade.

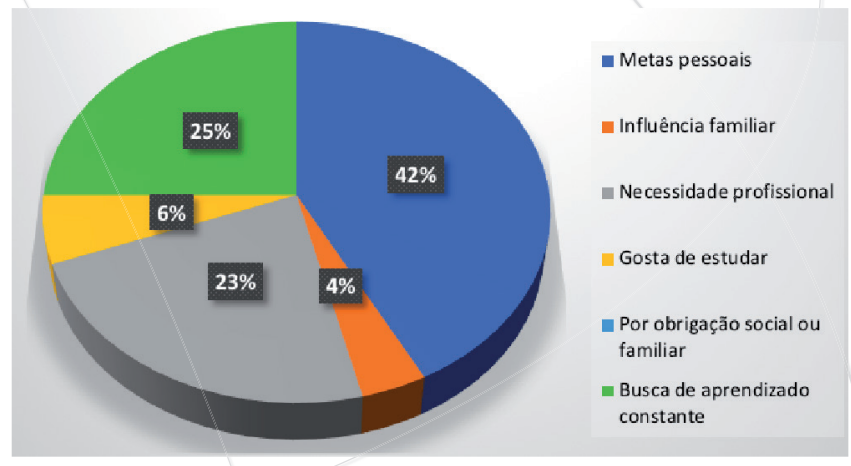

Fonte: Os autores (2018)

A figura 15 mostra que a maioria dos alunos procura fazer uma faculdade por metas pessoais (42\%), a seguir os motivos são busca de aprendizado constante (25\%), influência familiar (6\%) e necessidade profissional $(23 \%)$.

\section{Fase 3}

Considerando as respostas, desenvolveu-se um plano de aula juntamente com o desenvolvimento de metodologia ativa. Para tanto, um tema que fosse possível desenvolver essa metodologia foi escolhido para ser desenvolvido em dois cursos distintos, cujos resultados foram comparados.

Metodologias ativas usadas: Aula escolhida Housekeeping (plano de aula) com - Vídeos, Debates em grupos e no coletivo com a sala, desenvolvimentos de frases Motivadoras para cada uma das 5 fases do Housekeeping; contato com a UBS próxima da faculdade para implementação prática do método, fechamento dos resultados e prova ON-LINE, com as mesmas questões nos dois cursos. 
Fase 4

Aplicar as aulas considerando o plano de aula.

Lições aprendidas: (i) Deve-se dar mais tempo para as atividades com metodologia ativa, aparentemente quanto maior o grupo, mais tempo deve ser fornecido, é bom que o professor faça uma distribuição aleatória dos grupos, se usar recursos em aula (ii) o professor é responsável pelos recursos; (iii) a aplicação da ferramenta na UBS-Unidade Básica de Saúde (em torno da faculdade) não deu certo porque a liberação para uso das informações não foram dadas, sendo assim não seria possível que todos os alunos tivessem as mesmas informações. Nesse momento surgiu o plano "B": Cada aluno/grupo teria uma semana, ou seja, entre uma aula e outra para aplicar os 5 sensos em suas vidas pessoais ou profissionais, trazendo fotos das mudanças na aula seguinte; (iv) essa etapa aconteceu durante a semana (v) os alunos tiveram acesso ao material da aula antecipadamente, discutimos em grupo, apresentação de vídeos, e solicitou-se para a próxima aula frases de impacto para os 5 sensos do Housekeeping; (vi) Conversa com a diretora sobre a divulgação das frases na escola; a aprovação foi concedida, assim fechando as discussões sobre o tema; separou-se em grupos e, a cada dia, um grupo colava em todos os andares as frases de um senso; no dia seguinte retiravam as frases e colocavam outras para reforço de sua aplicação em toda a faculdade; (vii) Discussão na aula; validação da aplicação da ferramenta, com apresentação de cada grupo e (viii) aplicação de prova ON-LINE.

\section{Fase 6}

Análise dos resultados de cada prova ON-LINE. A sequência das questões está apresentada a seguir comparando os resultados da aula tradicional (1 aula) com metodologia ativa (2 aulas), considerando desempenho nas notas, quando a prova presencial aconteceu.

\section{PERGUNTAS SOBRE PERCEPÇÃO DA AULA COM METODOLOGIA ATIVA.}

1 Considerando a metodologia usada nas aulas de Housekeeping e a tradicional, qual você prefere?
Figura 16 - Qual a melhor aula tradicional ou com metodologias ativas?

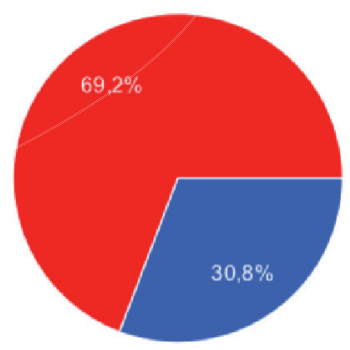

Tradicional

Metodologia ativa

Fonte: Os autores (2018)

A figura 16 apresenta que, após a experimentação da metodologia ativa, ela é preferência dos alunos com $60,2 \%$.

Comentários adicionais dos alunos, sem alteração textual: "Praticando, é a melhor forma de aprendizado; maior interação e aprendizado; a metodologia ativa coloca o aluno como seu principal agente pela sua aprendizagem, dando a ele mais responsabilidades sobre seu futuro; Só se aprende utilizando o conhecimento adquirido; Facilita a memorização das informações; é uma forma mais fácil para fixar o aprendizado na memória; Por ter mais flexibilidade; Aulas com a participação do aluno se tornam mais motivadoras; Aulas tradicionais trazem muito mais interação e dinâmica; Facilita o aprendizado; Tradicional, pelo fato que já estamos acostumados com a metodologia e toda mudança acaba gerando um desconforto no início; traz maior aprendizado; trabalhar mais com o pensar, não com o decorar, fazendo refletir melhor sobre o assunto; fáceis de entender e aplicável; a aula fica mais dinâmica; O método tradicional é claro e objetivo no que se quer chegar; Estimular o raciocínio; Porque é mais fácil de entender porque já tenho uma noção de conhecimento; eu prefiro que o professor coloque seu conhecimento a prova; porque já tenho um pouco de conhecimento, mais fácil de entender; Consigo absorver nos dois modelos, porém as aulas tradicionais nós temos uma grande quantidade, sem opção de diversificação; Isso me ajuda a pensar na matéria quando não estou em classe; Prefiro a metodologia ativa, porque com ela consegui procurar minhas próprias ferramentas para alcançar o compreendimento do con- 
texto. Ao ser desafiado a aplicar um conceito do $5 \mathrm{~S}$, me deparei com necessidade de definir por onde começar, identificar os desperdícios que poderiam ser melhorados e qual das ferramentas aplicar. Esses questionamentos foram desafiadores e motivaram-me a estudar sobre o assunto."

\section{Você descreveria que aulas com metodologia} ativa?

Figura 17 - O que é uma metodologia ativa para o aluno.

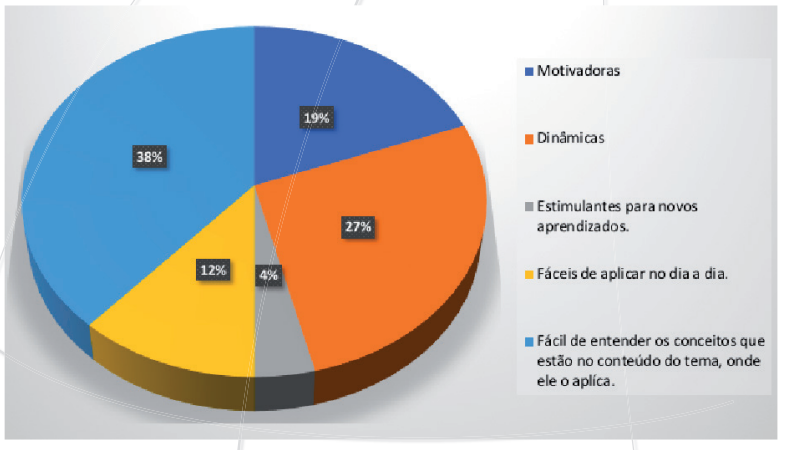

Fonte: Os autores (2018)

A figura 17, apresenta que, para os alunos, a metodologia ativa é: Fácil de entender (38\%), motivadora (19\%), dinâmica (27\%) e fácil de aplicar no dia a dia (12\%), embora não estimule novos aprendizados (4\%), segundo a percepção dos alunos.

Comentários adicionais dos alunos, sem alteração textual: "As aulas me motiva a continuar estudando, pois vejo que tenho muito que aprender; Mostra na prática ações teóricas; porque incentiva o aluno a buscar mais conhecimento para intender mais do assunto tratado em aula; Além de motivadoras, permitem que o aluno filtre só aquilo que é necessário para aplicar naquela atividade."

\section{Se você pudesse escolher teria mais aulas tradicionais ou com o formato da aula sobre 5 S's?}

Figura 18 - Como gostaria de continuar a aprender?

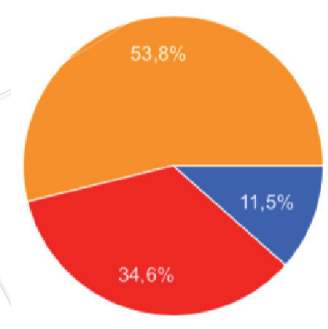

$$
\begin{aligned}
& \text { Aulas tradicionais. } \\
& \text { Aulas com metodologia ativa } \\
& \text { Um mix das duas }
\end{aligned}
$$

Fonte: Os autores (2018)

A figura 18 apresenta que os alunos gostariam de um mix entre as duas metodologias em sala de aula, evidenciado que $11,5 \%$ dos alunos preferem a metodologia tradicional.

Comentários adicionais dos alunos, sem alteração textual:

As respostas sobre a metodologia ativa e a prova tiveram como resultado:

Tabela 1 - Comparativo de resultados de aula tradicional $\mathrm{x}$ metodologia ativa.

\begin{tabular}{ccc} 
& Tradicional & Com metodologia ativa \\
\hline Questão & $\%$ acerto & $\%$ acerto \\
1 & $53 \%$ & $65,4 \%$ \\
2 & $12,5 \%$ & $19,2 \%$ \\
3 & $33,3 \%$ & $30,8 \%$ \\
\hline 4 & $91,7 \%$ & $84,6 \%$ \\
5 & $87,5 \%$ & $92,3 \%$ \\
6 & $29,2 \%$ & $53,8 \%$ \\
\hline
\end{tabular}

Fonte: Os autores (2018) 


\subsection{DISCUSSÕES SOBRE O TRABALHO NA FASE DA PESQUISA}

A pesquisa foi realizada em diversos cursos e os escolhidos para aplicação do resultado foram Fabricação Mecânica e Automação Mecânica, porque estavam na grade. Esses alunos estudam porque: (42,3\%) metas pessoais; (25\%) busca de aprendizado constante e $(23,1 \%)$ necessidade profissional.

A pesquisa apresentou que para se obter uma melhor absorção do conteúdo, o que possui mais resultado: com 55,8\% explicação do professor e 19,2\% exercícios em grupo; as disciplinas que os alunos mais gostam desenvolvem: $29,6 \%$ de lógica; $29,6 \%$ de conhecimento específico e 22,2\% de trabalhos em grupo; como critério de retenção de alunos na faculdade/universidade houve 4 que mais se destacaram com: $22 \%$ qualidade do professor; $20,3 \%$ metodologia em sala de aula, e $20,3 \%$ método de aprendizagem, e com $18,6 \%$ gratuidade do curso.

A periodicidade das provas, segundo os alunos pesquisados, é de $48 \%$ para as bimestrais. Em relação às aulas, para que estas possam ser produtivas devem conter: $46,2 \%$ atividades práticas; $25 \%$ explicações escritas em lousa e com 15,4\% discussões em grupo e $(61,5 \%)$ o professor deve dar informações que auxiliem o entendimento do tema apresentado; em $(71,2 \%)$ mix de teoria e prática contendo $(25 \%)$ exposições dialogadas e (25\%) estudos dirigidos e casos para que eles possam desenvolver, $(34 \%)$ raciocínio lógico na resolução de problemas da vida cotidiana e (33\%) saber interpretar conceitos pensamentos, fatos e opiniões, tanto oralmente como por escrito. Para os alunos pesquisados, características de liderança e outro idioma não são prioridades em sua educação, portanto clarificar a importância dessas competências é essencial durante o curso.

A falta de tempo $(62,5 \%)$ e $(28,5 \%)$ da didática do professor comprometem o desempenho do aluno/ discente na faculdade. Entre as competências que os alunos mais admiram nos professores/docentes temse: $(50 \%)$ conhecimento e $(37,5 \%)$ flexibilidade. Percebe-se que os alunos não gostam de aulas sem foco direcionado ao objetivo estudado, sendo justificado pela sua falta de tempo em estudar, por isso a prefe- rência em gostar de disciplinas que desenvolvam lógica, acesso fácil, disciplinado, organizado, participativo e estímulo ao diálogo em sala de aula.

Durante as aulas, o que motiva os alunos: atividades práticas com uso de vídeos que justifiquem a teoria, atividades que possibilitem respostas de casos reais; trocar experiências pessoais com os alunos; poder aplicar o conhecimento em vida prática; atividades em grupo; mesclar slides com lousa; aulas bem elaboradas; exercícios e explicações diretas; paciência para explicar a teoria e sua aplicação prática; aulas dinâmicas; bom relacionamento entre o professor e aluno; flexibilidade do professor para respostas diferentes da sua; metodologias que exigem o raciocínio e discussões sobre o tema.

Os maiores problemas para os alunos na faculdade são: ter que dividir trabalho e família; falta de tempo para estudar; didática e avaliações muito diferentes entre professores do mesmo semestre; falta de conhecimento do professor; aulas com slides sem exercício e conteúdo na lousa; conceitos antiquados de professores; reposições de aula sem planejamento; desafios pelo professor sem informação básica para que esse seja resolvido, desmotivando o aluno; falta de um canal para reclamações; língua inglesa; professor sem foco na matéria; dificuldades em manter foco nas atividades ou explicações.

Práticas que os alunos julgam adequadas para recuperar os alunos que têm baixo desempenho são: atividades focadas; atividades para o aluno recuperar nota; trabalho individual; explicações e práticas fáceis ou passar um trabalho; ensinar durante a aula; atividades complementares, dinâmicas participativas; se identificada no início, mudar a abordagem do tema; exercícios passo a passo; o aluno estudar livros e pesquisas no Youtube; cursos específicos da disciplina; trabalhos e avaliações práticas; utilizar alunos com bom desempenho para interagir com os demais alunos que têm avaliações baixas; rodízio de professores; monitoria para todas as matérias; apresentação de seminários; conversar com o aluno e propor algo novo; se for a maioria da sala repassar o conteúdo; indicar canais de estudos; o professor ser mais flexível com horários para alunos que trabalham ou fazem estágios. 


\subsection{DISCUSSÕES SOBRE O TRABALHO NA APLICAÇÃO DOS RESULTADOS DA PESQUISA}

$\mathrm{Na}$ aplicação do desenvolvimento da aula com metodologia ativa, constatou-se que o planejamento e aplicação de aulas com metodologias ativas são mais demorados em relação às aulas tradicionais. Os recursos utilizados são de responsabilidade do professor, pois aplicar o conhecimento dos alunos em organizações em torno da faculdade não é tão simples, é um processo que demanda tempo e planejamento; para agilizar as aulas, foi fornecido o material antecipadamente para a turma com metodologia ativa; para estimular o aprendizado e aplicar o conteúdo das aulas em uma situação real do seu cotidiano; as frases divulgadas na faculdade estimularam os demais alunos a pensarem no tema e interagirem; ao apresentar os resultados em sala, todos os alunos tiveram um aumento de possibilidades sobre o tema; a pesquisa pós -aplicação da metodologia e, em comparação com a sala sem seu uso, foi: $(69,2 \%)$ dos alunos preferiram a metodologia ativa, embora alguns alunos descreveram que mudanças geram desconfortos e a tradicional é mais objetiva.

Os alunos descreveram metodologias ativas como sendo: $(38,5 \%)$ fácil de entender os conceitos e onde ele se aplica; $(26,9 \%)$ dinâmicas e (19,2\%) motivadoras. Para $(53,8 \%)$ o melhor formato de aula é um mix entre tradicional e ativa, $(34,6 \%)$ preferem metodologias ativas e $(11,5 \%)$ metodologia tradicional.

Nas provas das 6 questões, em 4 questões os desempenhos dos alunos com metodologia ativa foram melhores, demonstrando que a metodologia ativa não prejudica o aprendizado dos alunos.

\subsection{CONCLUSÕES}

A maioria dos alunos de tecnologia procuram a faculdade como metas pessoais (42\%).

Os alunos entendem que a falta de tempo para estudar atrapalha seu desempenho, portanto, ao se aplicar conceitos ou atividades que não forem diretas aos objetivos do curso o professor precisa explicar ao aluno como isso poderá auxiliar sua melhora de performance.

Quanto à flexibilidade, a maioria dos alunos manifestou desejos pessoais de como recuperar suas notas, então, em aula inaugural ou primeira aula, os professores podem reforçar a legislação (horário, prova), procedimentos internos da faculdade (compensações e atividades administrativas), e sua flexibilidade em sala de aula, explicando as dificuldades em tratamentos individuais, para não ter problemas éticos e correr o risco de ser injusto com os demais da sala, por isso as decisões devem ser democráticas, sempre deixando a oportunidade do aluno se explicar.

Para sanar as dificuldades dos alunos é importante explicar a necessidade de teorias e disciplinas interdisciplinares, afinal o objetivo é formar o técnico/ gestor. Um exemplo claro é a língua inglesa, que será usada em qualquer atividade profissional; usa-se essa língua no nosso cotidiano.

Um destaque deve ser dado aos itens que o professor pode recuperar o aluno. Nesse aspecto, para ganhar nota, ele não reclama de atividades extras, entende que trabalho feito é nota ganha. Portanto, o professor deve explicar que os trabalhos devem ser pesquisados, escritos conforme normas ABNT e as notas terão critério de avalição. É importante que o aluno saiba que existe sacrifício e risco nas atividades.

Para as metodologias ativas pode-se afirmar que os alunos não têm uma qualificação pior com o seu uso, por isso um planejamento detalhado, para não perder objetividade e resultados pretendidos é necessário. Na pesquisa evidencia-se que $69,2 \%$ dos alunos preferem a metodologia ativa, considerando-a: motivadora, dinâmica e de fácil entendimento entre teoria e prática.

Os fatores estimuladores do conhecimento dos alunos foram: (1) Explicação do professor para desenvolver lógica e conhecimentos específicos, (2) Exercícios em grupo, (3) Provas que aconteçam em períodos de 2 meses, para não acumular matéria, (4) Atividades práticas que se apliquem à teoria na sala de aula, para auxiliar a resolução de situações reais com raciocínio lógico, interpretação de pensamentos e fatos tanto oralmente como por escrito, (5) Alternar entre slide, vídeos e lousa, para estimular os diversos tipos de inteligência; (6) Professores sempre atualizados, organizados e disciplinados; (7) Aulas dinâmicas, mesclando metodologias ativas e tradicionais; (8) Au- 
las objetivas, dando oportunidade de expressão dos alunos; (9) Reduzir atividades extras, para ajudar o aluno a se organizar, quando possível; (10) Fornecer links de canais e vídeos na internet, quando possível; (11) Estimular o uso de livros, grupos de estudos entre os alunos sobre os temas de aula; (12) Desenvolver atividades externas, no ambiente de trabalho, residência e em torno da faculdade, se possível em horário de aula, para aproximar a teoria do dia a dia;
(13) Apresentar para os alunos, em cada aula-tema, o objetivo por ocasião de seu término; (14) Ser flexível sem comprometer a ética, legislação e diretrizes institucionais e (15) Desenvolver cursos específicos para os alunos sobre os temas com maiores dificuldades e apresentá-los para a coordenação.

Fatores de retenção dos alunos na pesquisa foram: (1) Qualidade do professor; (2) Metodologia em sala de aula e (3) Gratuidade do curso. 


\section{REFERÊNCIAS}

CAMARGO, A. et al. EAD e o ensino de algoritmos: uma proposta de portal para o apoio ao processo de ensino e de aprendizagem de lógica e programação. ESUD 2017- XIV Congresso Brasileiro de Ensino Superior a Distância; III Congresso Internacional de Educação Superior a distância. p. 202-216. de 17 a 20 de outubro de 2017, Rio grande/RS.

DIESEL, A.; BALDEZ, A. L. S.; MARTINS, S. N. Os princípios das metodologias ativas de ensino: uma abordagem teórica. Revista Thema, v. 14, n. 1, p. 268288, 2017.

ONUBR. Transformando nosso mundo: a agenda 2030 para o desenvolvimento sustentável. Disponível em: https://nacoesunidas.org/pos2015/agenda2030/. Acesso em: 07 dez. 2018.

LAKATOS, E. M.; MARCONI, M. A. Metodologia do trabalho científico: procedimentos básicos, pesquisa bibliográfica, projeto e relatório, publicações e trabaIhos científicos. 7. ed. 10. Reimpr. São Paulo: Atlas, 2015.

LAZARO, A. C.; SATO, M. A. V.; TERAZI, T. C. R. Metodologias ativas no ensino superior: o papel do docente no ensino presencial. CIET - Congresso Internacional de Educação e Tecnologias, 16/06 a 13/07. São Carlos, 2018.

MACHADO, A. B. et al. Práticas inovadoras em metodologias ativas. Florianópolis: Contexto digital, 2017.

MASETTO, M. T. Inovação na aula universitária: espaço de pesquisa, construção de conhecimento interdisciplinar, espaço de aprendizagem e tecnologias de comunicação. Perspectiva. Florianópolis, V.29, n. 2, 597-620, jul./dez. 2011.

MORAN, J. Metodologias ativas para uma aprendizagem mais profunda. 2013. Disponível em: http:// www2.eca.usp.br/moran/wp-content/uploads/2013/12/ metodologias_moran1.pdf. Acesso: 29 nov. 2018.
Mudando a educação com metodologias ativas. 2015 Disponível em: http://www2.eca.usp. br/moran/wp-content/uploads/2013/12/mudando_moran.pdf. Acesso em: 02 dez. 2018.

MORIOKA, S. N.; DANTAS, M. P.; SILVA, J. V. Aplicação de metodologias ativas de ensino da gestão da produção: análise da aplicação de dinâmicas de aprendizagem baseada em equipes. CONBREPROVIII Congresso Brasileiro de Engenharia de Produção. Ponta Grossa, PR, Brasil. 06 a 08 de dezembro 2018.

OLIVEIRA, G. F.; FARIAS, F. G. Implantação do programa 5 S: um estudo de caso em uma microempresa do ramo de confecção. CONBREPRO-VII Congresso Brasileiro de Engenharia de Produção. Ponta Grossa, PR, Brasil. 06 a 08 de dezembro 2017.

PAIVA, G. M.; ZOCCHE, L. Análise da implantação da metodologia $5 S$ no setor de manutenção em uma empresa de grande porte no Estado do Paraná. COBREPRO- VII Congresso Brasileiro de Engenharia de Produção. Ponta grossa, PR, Brasil. 05 a 07 de dezembro de 2018.

PAMBOUKIAN, S. As competências requeridas no século XXI dos egressos dos cursos superiores em tecnologia mecânica e soldagem da FATEC-SP. Dissertação para Título de Mestre em Gestão e Desenvolvimento da Educação. Programa de Mestrado Profissional em Gestão e Desenvolvimento da Educação Profissional. CENTRO Estadual de Educação Tecnológica Paula Souza. São Paulo, 2018.

POISSON. Educação no século XXI. 1. ed. Belo Horizonte, MG: Poisson, 2018. v.5

QUINTILHANO, S. R. et al. Metodologias ativas de aprendizagem: aplicação das múltiplas representações em disciplina de simulação no curso de Engenharia de Produção da UTFPR Campus Londrina. 
CONBREPRO-VII Congresso Brasileiro de Engenharia de Produção. Ponta Grossa, PR, Brasil. 06 a 08 de dezembro 2017.

SILVA, A. L. E. et al. Percepção e análise do programa $5 \mathrm{~S}$ em uma empresa prestadora de serviço. GEPROS. Gestão da Produção, Operações e Sistemas, Bauru, Ano 11, n. 3, p. 23-37 jul./set. 2016.
ZALUSKI, F. C.; OLIVEIRA, T. D. Metodologias ativas: uma reflexão teórica sobre o processo de ensino aprendizagem. CIET - Congresso Internacional de Educação e Tecnologias. UFSCAR, São Carlos, 2018.

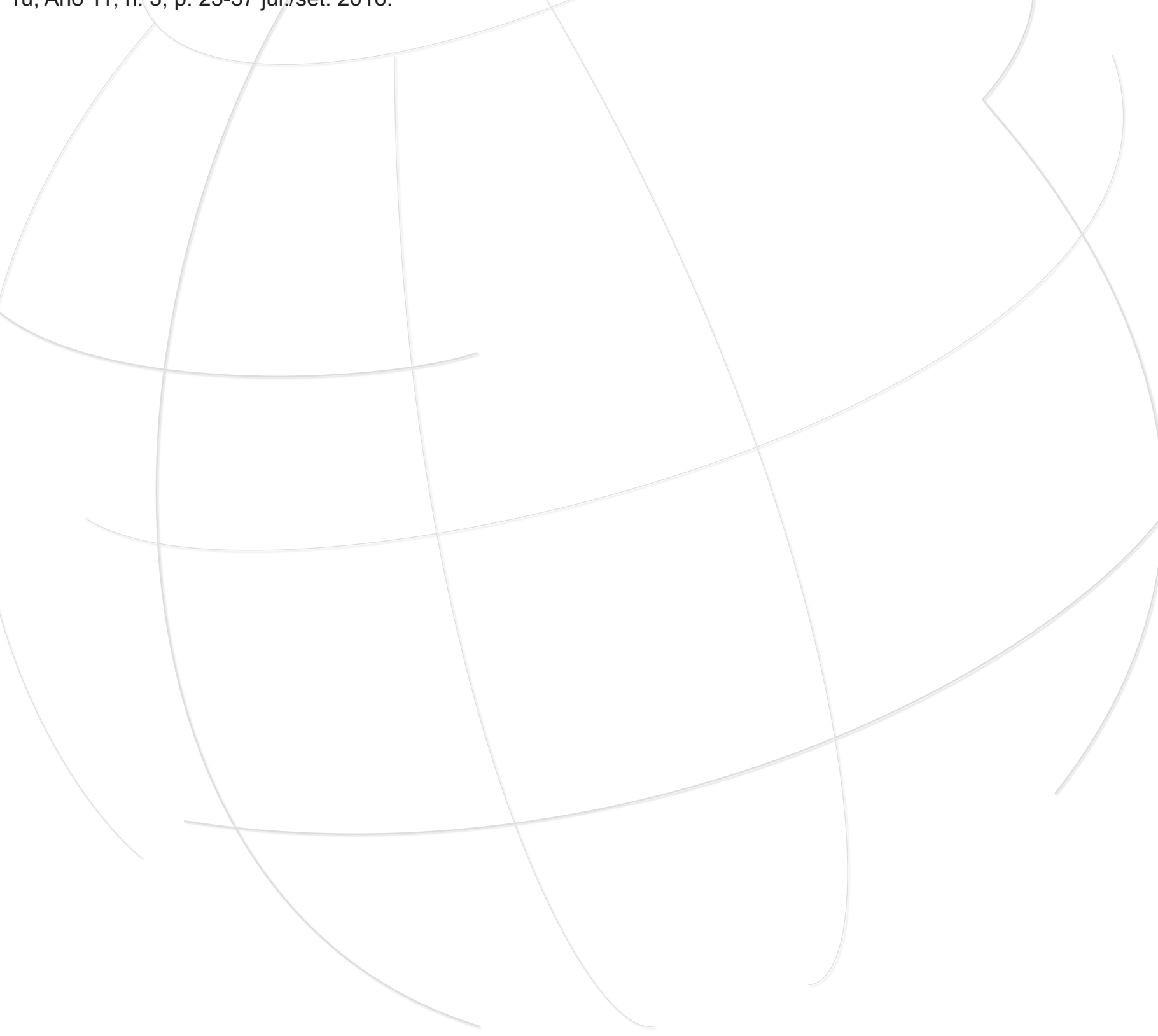

